\title{
Health Inequalities and Relational Egalitarianism
}

\author{
J. Paul Kelleher \\ University of Wisconsin-Madison
}

To appear in Rebecca Walker, Mara Buchbinder, and Michele Rivkin-Fish (eds.) Understanding

Health Inequalities and Justice: Bridging Perspectives for New Conversations (University of North Carolina Press, in press)

\begin{abstract}
Much of the philosophical literature on health inequalities seeks to establish the superiority of one or another conception of luck egalitarianism. In recent years, however, an increasing number of self-avowed egalitarian philosophers have proposed replacing luck egalitarianism with alternatives that stress the moral relevance of distinct relationships, rather than the moral relevance of good or bad luck. After briefly explaining why I am not attracted to luck egalitarianism, I distinguish and clarify three views that have been characterized in the philosophical literature as forms of relational egalitarianism. I call these three relational views equality of treatment, equality of concern, and social egalitarianism. I argue that each deserves the title "egalitarianism" and (more importantly) that these three views are not competitors; rather, each brand of relational egalitarianism describes a plausible plank of distributive justice that bears on the evaluation of health inequalities and on the political institutions that create, sustain, or exacerbate them. To illustrate this pluralistic relational egalitarian approach, I draw on a case study by Horton and Barker (this volume) to discuss how each of the three planks might be brought to bear on the evaluation of oral health disparities among the children of migrant Latino farmworkers in California.
\end{abstract}

\section{Introduction}


If one wishes to evaluate inequalities in health from the perspective of justice, it is natural to turn to philosophical conceptions of egalitarianism. Such views aim to explain why inequalities (or at least certain inequalities) are morally problematic, and why social and political institutions that create, sustain, or exacerbate health inequalities are unjust and need repair. There is, however, a vigorous debate within political philosophy as to how egalitarianism should be conceived. In recent years, a broad division has emerged between so-called luck egalitarians, on the one hand, and "relational" egalitarians, on the other. The main aim of this chapter is to explain this debate, and to distinguish further between three types of relational egalitarianism. Although I will not offer a comprehensive critique of it, I will explain why I am not attracted to luck egalitarianism. Then, after distinguishing between the three types of relational egalitarianism, I will suggest that these should not be viewed as competitors; rather, each describes a plausible plank of distributive justice that bears on the evaluation of health inequalities and the political institutions that create, sustain, or exacerbate them. To illustrate this pluralistic egalitarian approach, I will draw on a case study by Horton and Barker (this volume) to discuss how each of the three planks might be brought to bear on the evaluation of oral health disparities among the children of migrant Latino farmworkers in California.

\section{Luck Egalitarianism and Relational Egalitarianism}

There are many versions of luck egalitarianism, but they all endorse the claim that inequalities are pro tanto unjust, unless they can be shown to result from the responsible choices of individuals. ("Pro tanto" indicates that the injustice can be outweighed by other moral factors; for example, a policy that widens unchosen inequalities may nevertheless be all-thingsconsidered just if the increase in inequality is morally outweighed by significant improvements 
in the well-being of the worst off.) Luck egalitarians believe that (pro tanto) injustice attaches to inequalities that result from bad brute luck, but not to inequalities traceable to individuals' responsible choices or gambles. ${ }^{1}$ Different versions of luck egalitarianism focus on different kinds of inequality—some focus on inequalities in health as such, whereas others care about health only insofar as health bears on the wider category of well-being. But again all versions tie judgments of justice and injustice to facts about chance and choice.

For the moment, let us assume that all relevant inequalities (whether inequalities in health or inequalities in well-being) arise from bad brute luck (and thus not from gambles and choices for which individuals can be held responsible). Luck egalitarianism would thus condemn the inequalities. But why? Consider the following diagram, which replicates a diagram first drawn by Michael Marmot and discussed in his book The Status Syndrome. ${ }^{2}$

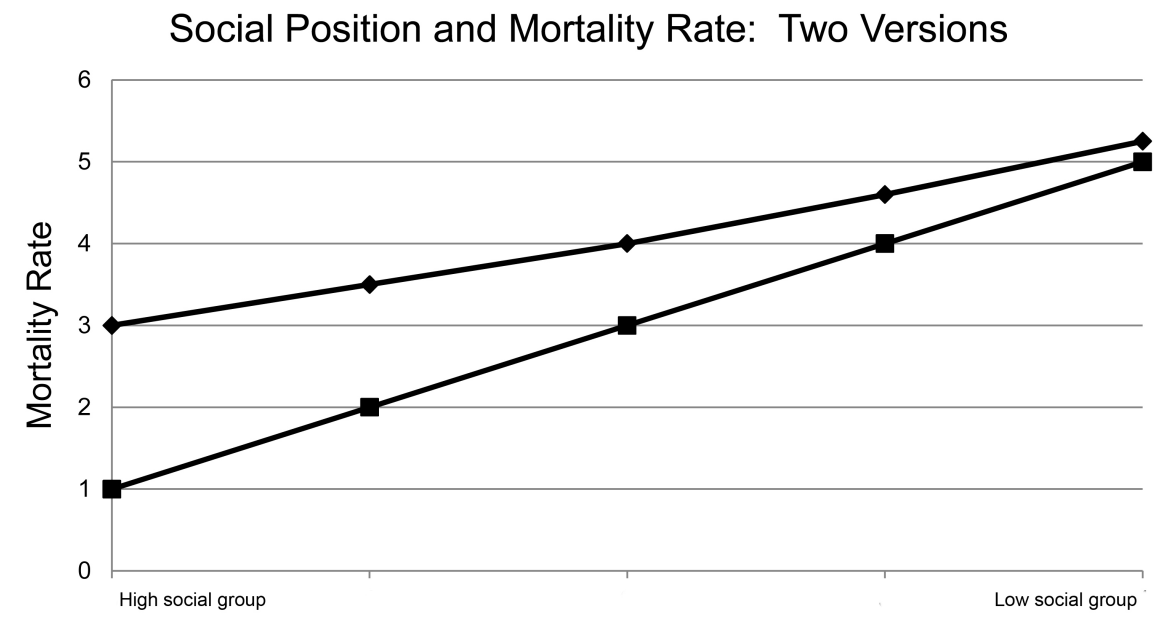

The diagram shows the mortality effects of two different policies on four social groups arranged from left to right in descending order of social advantage. Call the two policies Square

\footnotetext{
${ }^{1}$ It is of course not easy — and perhaps it is impossible - to distinguish choices and outcomes for which people are responsible from those that result from bad brute luck. For further discussion, see Voigt, "Appeals to Personal Responsibility."

${ }^{2}$ Marmot, The Status Syndrome, 246.
} 
(indicated by the bottom graph) and Diamond (indicated by top graph). Suppose Diamond reflects current policy and we are considering a move to Square. Should we make the move? Square would obviously lead to greater health inequalities than Diamond, but Square also offers Pareto improvements with respect to life expectancy, since each social group in Square has lower mortality than the corresponding social group in Diamond. (Assume that changing policies would not change who is in which group.) Marmot drew the diagram during a conversation with the health economist Angus Deaton. Deaton then asked Marmot whether he cared more about reducing distributive inequalities than he did about reducing ill health. Here's how Marmot responded:

I demurred. [Deaton] was in no doubt that all economists would choose the bottom graph because everyone is better off...[He] suspected that I went for the one with less inequality where everyone suffered more...It is my view that we should reject both alternatives and aim for a society where health for everyone has improved and inequality is less. $^{3}$

This answer of Marmot's probably did not satisfy Deaton. For Deaton was trying to call attention to the downside of claiming that equality itself is intrinsically important. Marmot's response suggests that he endorses (or would endorse) a philosophical position that very often underlies luck egalitarian views. This position is known as telic egalitarianism, and it says simply that equality is intrinsically good, and inequality intrinsically bad. Larry Temkin is a leading proponent of telic egalitarianism, and he has elsewhere offered a Marmot-like response to scenarios similar to Square-vs.-Diamond that force one to choose between greater equality and less sickness and death. As Temkin puts it:

${ }^{3}$ Ibid., 245-6. 
The essence of the egalitarian's view is that comparative unfairness is bad, and that if we could do something about life's unfairness, we have some reason to. ${ }^{4}$ $[\ldots]$

But, the anti-egalitarian will incredulously ask, do I really think that there is some respect in which only some being blind is worse than all being blind? Yes. Does this mean that I think it would be better if everyone else was blind? No. As noted previously, equality is not all that matters. But it does matter some. ${ }^{5}$

Temkin here associates unchosen inequalities with what he calls "comparative unfairness." In Temkin's view, it is simply unfair when some have better health than others through no fault of their own. It is a short step from here to the conclusion that unchosen inequalities are unjust, as many people believe in a tight connection between fairness and justice. Temkin admits, however, that this unfairness generates only a pro tanto reason to eliminate the inequality. Thus, in a scenario like Square-vs.-Diamond, Temkin's view leaves open the possibility that it is ultimately more important to avoid Diamond's costs in health and well-being than it is to secure its more equal distribution. Nevertheless, telic egalitarianism, or something quite like it, is at the heart of most luck egalitarian approaches to distributive justice.

Now, in the very large literature on telic egalitarianism there are two objections to it that are worth noting here. The first objection maintains that telic egalitarianism has little right (and certainly no exclusive right) to the name "egalitarianism." Elizabeth Anderson was among the first to lodge this objection. She writes: "There must be a better way to conceive of the point of equality. To do so, it is helpful to recall how egalitarian political movements have historically conceived of their aims....Inequality referred not so much to distributions of goods as to

\footnotetext{
${ }^{4}$ Temkin, "Egalitarianism Defended," 775.

${ }^{5}$ Ibid., p. 780; emphasis in original.
} 
relations between superior and inferior persons." ${ }^{, 6}$ More recently, Daniel Hausman and Matt Waldren argue that six discrete objectives_-none of which resembles telic egalitarianism_- "have been prominent among the objectives of those who have fought under the banner of equality." I will return to Anderson's and Hausman's and Waldren's views below.

A second objection to telic egalitarianism would apply even if telic egalitarians agreed that other views also merit the label "egalitarian." This second objection claims that distributive equality has no moral importance because it is not connected in the right way to the interests of individuals. Roger Crisp puts it like this: "[T]he worry arises from the idea that what matters morally could be something that was independent from the welfare of individuals." ${ }^{8}$ Since pursuing equality in Square-vs.-Diamond (and in other examples Temkin himself constructs) would harm everyone's interests in absolute terms, Crisp finds it hard to see why one should care intrinsically about distributive equality at all. Where does its value come from? As Martin O’Neill writes, “On the Telic view...the ideal of equality can seem merely arithmetic, instead of being a properly intelligible political value." ${ }^{99}$ For this reason, Hausman and Waldren refer to telic egalitarianism as "fundamentalist egalitarianism," since "it relies on what it regards as a fundamental intuition" about the injustice of unchosen inequalities. ${ }^{10}$ In a scenario like Squarevs.-Diamond, telic/fundamentalist egalitarians "can only thump their guts... The problem is that...their argument for equality does not share anything with arguments for competing moral concerns."11

\footnotetext{
${ }^{6}$ Anderson, "What is The Point of Equality?," 312.

${ }^{7}$ Hausman and Waldren, "Egalitarianism Reconsidered," 578.

${ }^{8}$ Crisp, "Equality, Priority, and Compassion," 747.

${ }^{9}$ O’Neill, "What Should Egalitarians Believe?" 139.

${ }^{10}$ Hausman and Waldren, "Egalitarianism Reconsidered," 569.

${ }^{11}$ Ibid., 574.
} 
I am very sympathetic to Crisp's, O'Neill's, and Hausman and Waldren's doubts about the intrinsic value of distributive equality, and thus I am sympathetic to this second objection to the telic luck egalitarian principle. Many philosophers who lack the fundamentalist intuition about the intrinsic value of distributive equality will suggest that equality only appears to be valuable because the pursuit of equality so often overlaps with the pursuit of arrangements that benefit the worst off. But these philosophers are quick to note that a commitment to improving the prospects of the worst off is not the same as a commitment to distributive equality. After all, sometimes improving the situation of the worst off will require increasing inequalities (as it would in a move from Diamond to Square). In order to give voice to these non-telic-egalitarian concerns, Derek Parfit introduced prioritarianism, the view that "Benefitting people matters more the worse off these people are." ${ }^{\prime 12}$ Thus on a prioritarian view, there might be nothing at all wrong with a policy that maximally benefits the worst off while also increasing distributive inequality. Temkin, by contrast, wants to say that although such a policy might be all-thingsconsidered morally permissible (or even morally required), it is nevertheless morally regrettable because it clashes with telic luck egalitarianism. But if Crisp and O'Neill and Hausman and Waldren are all correct to doubt or reject the fundamentalist intuition that underlies luck egalitarianism, then prioritarianism will be attractive because it is an ideal that is quite clearly connected to the interests of persons. For whenever prioritarianism recommends a policy, that is because the policy will at least make someone better off. Telic egalitarianism cannot say the same.

While I believe that prioritarianism is an improvement over telic egalitarianism (and thus over luck egalitarianism), I do not believe it provides the basis for a plausible conception of

${ }^{12}$ Parfit, "Equality and Priority," 213. 
distributive justice. To see why, note that as Parfit paints the view, prioritarianism requires a prioritarian response to all the needs one is in a position to address. As he puts it:

[The Priority View] naturally has universal scope. If it is more important to benefit one of two people, because this person is worse off, it is irrelevant whether these people are in the same community, or are aware of each other's existence. The greater urgency of benefitting this person does not depend on her relation to the other person, but only on her lower absolute level. ${ }^{13}$

Drawing on a similar interpretation of prioritarianism, Richard Norman argues that the prioritarian perspective derives from "the standpoint of benevolent and sympathetic concern." Norman goes on to distinguish "the ethics of benevolence" from the ideal of social justice, thereby implying that prioritarian concern is what we are obligated to display to others regardless of our particular relationship to them. ${ }^{14}$ Given this, I fear that both telic egalitarianism and prioritarianism run afoul of an important objection that W. D. Ross made long ago against utilitarianism. Ross writes:

In fact the theory of 'ideal utilitarianism'... seems to simplify unduly our relations to our fellows. It says, in effect, that the only morally significant relation in which my neighbours stand to me is that of being possible beneficiaries by my action. They do stand in this relation to me, and this relation is morally significant. But they may also stand to me in the relation of promisee to promiser, of creditor to debtor, of wife to husband, of child to parent, of friend to friend, of fellow countryman to fellow countryman, and the like; and each of these relations is the foundation of a prima facie

\footnotetext{
${ }^{13}$ Ibid., 214.

${ }^{14}$ Norman, "Equality, Priority, and Social Justice," 184, 185.
} 
duty, which is more or less incumbent on me according to the circumstances of the case. $^{15}$

Ross agreed with utilitarianism that there is always an important moral reason to promote others' well-being, regardless of their relationship to us. And he might well have agreed with prioritarianism - if he had known about it — that the well-being of the worst off deserves some special priority. But Ross starkly departs from utilitarianism, prioritarianism, and telic egalitarianism in stressing the distinct moral importance of certain special relationships. It is, of course, not news that utilitarianism sees nothing intrinsically morally important about special relationships; and Parfit observes that prioritarianism is similar to utilitarianism in this regard. And though Parfit is correct when he says that telic egalitarianism is intrinsically concerned with relativities, the relativities at issue here involve brute comparisons between certain features of people's circumstances - e.g. their health or well-being - rather than on any distinctive social, familial, political, or otherwise interpersonal relationship the people themselves might stand in with others. What would happen, then, if instead of embracing telic egalitarianism or the equally non-relational alternative of prioritarianism, we follow a more Rossian path and seek a relational egalitarianism? What would a decidedly relational egalitarianism look like?

\section{Three Kinds of Relational Egalitarianism}

Although they are not always characterized as such, I believe there are at least three types of relational egalitarianism on offer in the philosophical literature. These views highlight different kinds of morally important relationships we can stand in with others, rather than simply highlighting the bare fact that one person (or group of persons) has better health or greater well-

\footnotetext{
${ }^{15}$ Ross, The Right and the Good, 19. Ross uses "prima facie" to make the qualification I have been making with "pro tanto."
} 
being than another. Each of these relational views has its own distinctive reasons for calling itself "egalitarian," as I will explain. What they share is the conviction that if an ideal of equality is morally important for distributive justice, it must be reinterpreted as something other than mere similarity of condition between individuals who bear no further distinctive relation to one another. Moreover, while all three relational egalitarianisms are competitors to telic luck egalitarianism, they are not necessarily competitors with each other. Indeed, after sketching each of the three in this section (with a focus on their implications for health), I will explain more fully in sections 4 and 5 how these three views can be combined into a single framework that can guide the formation of health policy.

First Type of Relational Egalitarianism: Equal Treatment

The first type of relational egalitarianism comes separately from Thomas Pogge and Thomas Nagel. In a paper entitled "Relational Conceptions of Justice: Responsibilities for Health Outcomes," Pogge writes:

My view on justice in regard to health is distinctive in two ways. First, I hold that the strength of our moral reasons to prevent or to mitigate particular medical conditions depends not only on what one might call distributional factors, such as how badly off the people affected by these conditions are in absolute and relative terms, how costly prevention or treatment would be, and how much patients would benefit from given treatment. Rather, it depends also on relational factors, that is, on how we are related to the medical conditions they suffer. ${ }^{16}$

To illustrate, suppose you negligently hit a child while driving, injuring her badly. Upon rushing her to the hospital, you learn that she is in critical condition and requires a blood transfusion. Her ${ }^{16}$ Pogge, "Relational Conceptions," 135. 
blood type is rare and, as it happens, matches yours. She needs a lot of blood, and you are prepared to donate. However, the doctor also informs you that two other children were also recently admitted in need of that same rare blood type. Each needs half the amount you need to give to the girl to save her life, and you cannot safely donate enough to save all three. The doctor asks you whether you'd like to donate your blood and what you want done with it. It is Pogge's view that you have a stronger obligation to the girl than to the two other children, and that this traces to the way in which you are related to her current condition. In particular, you caused it. So although you can save more lives by letting the girl die and giving your blood to the other two children, Pogge believes you are morally required to choose the option that fails to maximize the number of lives saved. Call this kind of relational view causal relationism, since it says that our causal connections with others are relevant for assigning moral responsibility.

So construed, only a strict consequentialist will reject causal relationism wholesale. But Pogge takes this non-consequentialist line quite a bit further, arguing that a duty to redress another's neediness is a duty of justice only if it flows from causal relationism. Consider another of his health-related examples:

There are...extremely harsh natural environments where a man with a higher metabolic rate cannot meet his extra food needs simply by moderating his discretionary spending a bit or by working a little overtime. In such a context, decent people will make every effort to ensure that the man will have enough to eat. They will do so as a matter of basic human solidarity, realizing that, given his constitution, he simply cannot survive on the fruits of his own labor. But does he have a justice claim to such support, can he demand it as a matter of right? Listen to what such justice claim would sound like: "I have a higher metabolic rate than you all. As a consequence, I need 50\% percent more food each day to 
be equally well nourished. Six hours of labor are needed to produce this additional food. You five therefore owe it to me as a matter of justice to work an extra hour each day along with me to produce the extra food I need." If this is not a plausible claim, then we should recognize, I think, that there are moral requirements that, however stringent and categorical, are not demands of justice. ${ }^{17}$

Pogge elsewhere admits that this approach to justice "seems committed to the callous (if not cruel) view that we, as a society, need do no more for persons whose health is poor through no fault of ours than for persons in good health". ${ }^{18}$ Yet as is indicated in the final line of the long quotation above, Pogge prefers instead to draw a distinction between moral obligations (which might be heavily needs-based) and obligations of justice (which, he says, are not). It is then open to partisans of causal relationism to "speak of duties of humanity or solidarity" that are "quite stringent" but which "do not correlate with rights." 19

So how can the idea of causal relationism be used to construct a brand of relational egalitarianism? Pogge's answer is that causal relationism entails that "the core of egalitarian liberalism" consists in "the idea that a liberal society, or state, ought to treat all its citizens equally in terms of helps and hindrances. Such equal treatment need not be equality-promoting treatment. Preexisting inequalities in, for example, genetic potentials and liabilities... are not society's responsibility." ${ }^{20}$ Thus while telic egalitarianism is equality-promoting —-that is, it sees intrinsic value in equal outcomes-Pogge's equality of treatment view ignores outcomes and focuses solely on equalizing the benefits that society bestows and the burdens it imposes. For many of the same reasons as Pogge, Thomas Nagel has also defended "the deontological theory

\footnotetext{
${ }^{17}$ Pogge, "A Critique of the Capability Approach," 53.

${ }^{18}$ Pogge, "Responsibilities for Poverty-Related Ill Health," 76.

${ }^{19}$ Pogge, "A Critique of the Capability Approach," 53.

${ }^{20}$ Pogge, "Responsibilities for Poverty-Related Ill Health," 75.
} 
of justice" that "centres on equal treatment rather than the avoidance of inequality in the broadest terms. ${ }^{, 21}$ Like Pogge's, Nagel's view restricts "injustice to certain specifically social causes of inequality, whose avoidance takes precedence over the general welfare and other goals," including the purely distributive goals of telic egalitarianism. ${ }^{22}$

To see why this might be called an egalitarian view, it will help to have a more concrete example of what Pogge and Nagel mean by equal treatment. Consider then the reasonable complaint that a blind person might lodge in a society that caters more to the needs of the sighted than to the blind. The telic egalitarian would highlight the unchosen, unequal, and thus unfair outcomes that result when only the sighted can easily navigate their social world. By contrast, Pogge prefers to say:

I understand that the present organization of our society is less appropriate to your mental and[/or] physical constitution than to those of most of your fellow citizens. In this sense, our shared institutional order is not affording you genuinely equal treatment. To make up for the ways in which we are treating you worse than most others, we propose to treat you better than them in other respects. For example, to make up for the fact that traffic instructions are communicated through visible but inaudible signals, we will provide free guide dogs to the blind. In doing so, our objective is that our institutional order as a whole should afford you genuinely equal treatment. ${ }^{23}$

Here, equal treatment involves equalizing the overall balance of benefits and burdens that flow from active social policy choices. It does not involve equalizing resulting health or well-being. Thus, if there are further disadvantages in well-being that attend blindness but which are not

\footnotetext{
${ }^{21}$ Nagel, "Justice and Nature," 305-6.

${ }^{22}$ Ibid, 313.

${ }^{23}$ Pogge, "A Critique of the Capability Approach," p. 31.
} 
redressed by policies affording equal treatment, Pogge and Nagel do not believe that justice requires further redress.

Equality of treatment, so construed, is a form of relational egalitarianism because its understanding of what must be equalized stems from a prior commitment to causal relationism. Causal relationism, in turn, holds that the strength of one's reason to address neediness depends largely upon one's causal relation to the needs in question. On this view, once the needs that one has caused (or helped to cause) have been redressed, one has strong reason to address residual needs only if doing so is required to ensure that social policies distribute socially created benefits and burdens equally among members of society.

\section{Second Type of Relational Egalitarianism: Equality of Concern}

The distinction between moral duties and duties of justice seems clearly important, but one might doubt that Pogge and Nagel have drawn the line in the right place. For while Pogge and Nagel are surely correct to highlight justice-based duties to redress needs to which one is causally related, Pogge and Nagel do not take pains to argue against justice-based duties that arise out of the way one is related to the people who suffer the needs. Yet as Ross stresses, these latter sorts of duties arise all the time and can be quite stringent. They are present, for example, when a parent has a duty to respond to the needs of a sick child, or perhaps when a citizen has a duty to help provide health care to a soldier whose health need is not traceable his or her military service. In each of these cases, what we owe others has to do with the special interpersonal relationship we bear to them, not the special causal relationship we might bear to their need. So here we have a second kind of relational view. Call it interpersonal relationism. Interpersonal relationism is a component of lots of distributive justice frameworks, and it is the form of 
relationism discussed in Samuel Scheffler's influential paper, "Relationships and Responsibilities." Scheffler's discussion focuses on responsibilities that arise out of noninstrumentally valuable relationships, but it is not obvious that interpersonal relational responsibilities cannot also arise in the context of purely instrumentally valuable relationships. Nevertheless, I shall follow Scheffler in viewing interpersonal relational responsibilities as requiring a "dispos[ition]...to see that [other] person's needs, interests, and desires as, in themselves, providing me with presumptively decisive reasons for action, reasons that I would not have had in the absence of the relationship. ${ }^{24}$ In other words, they require a certain degree of concern for another's well-being.

Just as Pogge and Nagel built a version of relational egalitarianism (i.e. equality of treatment) around the more general idea of causal relationism, so too can a distinct version relational egalitarianism be built around the general idea of interpersonal relationism. Such a view would hold that distributive justice generates duties of equal concern for those to whom one stands in especially morally relevant political relationships. Views along these lines have been defended separately by Ronald Dworkin and Richard W. Miller. According to Dworkin, "[e]qual concern is the sovereign virtue of political community," for "[n]o government is legitimate that does not show equal concern for the fate of all those citizens over whom it claims dominion and from whom it claims allegiance. ${ }^{25}$ Likewise, Miller claims that, "Equal concern is the more appropriate standard [of social justice] because it better reflects the moral significance of democratic citizenship. For equal concern...expresses the proper valuing of the institutional loyalties on which a well-ordered democracy depends. ${ }^{, 26}$ According to Miller, the proper way to

\footnotetext{
${ }^{24}$ Scheffler, Boundaries and Allegiances, 100.

${ }^{25}$ Dworkin, Sovereign Virtue, 1.

${ }^{26}$ Miller, "Too Much Inequality," 298.
} 
value others' institutional loyalties — i.e. loyalty to a shared political project — is "by showing special loyalty to them, displayed in special concern for their needs." 27

The requirements of equal concern embodies what I have elsewhere called a "supplyside" requirement. ${ }^{28}$ That is, it does not in the first instance enjoin a specific pattern or level of benefits that individuals are to possess or enjoy; rather, it enjoins a degree of other-regarding concern that is to flow from the provider of justice (here most plausibly the political community as a corporate entity) to the recipients of justice (the members conceived as individuals). Thus, unlike both telic egalitarianism and Parfit's prioritarianism, which focus on the "demand-side" issue of individuals differ in the amount of health or well-being they enjoy, equality of concern stresses the supply-side factor of displaying the proper attitudes toward, and dispositions to help, those in need.

Drawing in part on both Dworkin and Miller, I have argued elsewhere that equality of concern is indeed a genuine requirement of distributive justice. ${ }^{29}$ But my goal here is only to explain how that view can be seen as a distinct brand of relational egalitarianism. It is egalitarian because the concern displayed to each of a given set of individuals is to be equal. And it is relational insofar as the duty to show special concern is grounded in facts about interpersonal relationships that tie certain individuals to one another. Dworkin suggests how these two elements can be combined to yield a distinctive view (or at least a distinctive plank of justice). He writes, "As individuals we owe all other human beings a measure of concern, but we do not owe them concern equal to that we have for ourselves, our families, and others close to us. ${ }^{, 30} \mathrm{He}$ continues, "A legitimate government must treat all those over whom it claims dominion not just

\footnotetext{
${ }^{27}$ Miller, Globalizing Justice, 43.

${ }^{28}$ Kelleher, "Capabilities versus Resources."

${ }^{29}$ Kelleher, "Beneficence, Justice, and Health Care."

${ }^{30}$ Dworkin, Is Democracy Possible Here?, 95; emphasis in original.
} 
with a measure of concern but with equal concern. I mean that it must act as if the impact of its policies on the life of any citizen is equally important.."31 I interpret Dworkin as claiming that certain features of the domestic political relationship justify governments (I prefer to speak of political communities) in showing strong and equal concern for each member of society. This is what makes it a form of relational egalitarianism.

A famous example of Thomas Nagel's is, I think, useful in beginning to tease out more practical implications of the equal concern view. (For our purposes, it is best to ignore the interpretive question of what Nagel would say is the connection between this example from 1979 and his later endorsement of causal relationism and the equal treatment view.) The example begins by asking us to imagine that Nagel has one healthy child and one suffering from a painful disability. Suppose now that he must make a choice between moving to a city where the second child could receive medical treatment but which would be unpleasant for the first child, or moving to a semi-rural suburb where the first child alone would benefit. Nagel stipulates that "the gain to the first child of moving to the suburb is substantially greater than the gain to the second child of moving to the city." He then claims that, "If one chose to move to the city, it would be an egalitarian decision. It is more urgent to benefit the second child, even though the benefit we can give him is less than the benefit we can give the first child. ${ }^{32}$ In response to these claims, Parfit argued that Nagel had confused the ideas of equality and priority. For Nagel's discussion clearly suggests that he really does not care about equality at all; rather, his focus is instead on making the worst off child as well off as possible. ${ }^{33}$ But Parfit's diagnosis ignores the fact that Nagel's example seems intended to illustrate the supply-side phenomenon of equal

\footnotetext{
${ }^{31}$ Ibid., 97.

${ }^{32}$ Nagel, "Equality," 124.

${ }^{33}$ Parfit, "Equality and Priority," 215-16.
} 
concern. Thus Parfit can be right that if one fundamentally cares about improving the situation of the worst off, then one should not fundamentally care about distributive equality in the way the telic luck egalitarian does. That is, one should not care about brute arithmetic equality between people's health or well-being, for it is (as we have seen) conceivable that the only way to improve the lot of the worst off is via a policy that improves the better off even more, thereby widening the gap. But—and here's the key point—even if one does not fundamentally care about distributive equality between people's health or well-being, one can maintain that each is entitled to robust and equal concern. And according to Nagel, equal concern for the worst off is precisely what justifies being especially attentive to their needs. That is the very point of the example: while he loves his two children equally, and is therefore equally concerned for them, he also rightly views the needs of the worst off child "as being ahead in the queue, so to speak.",34 Nagel's example, therefore, demonstrates how something like a prioritarian response to differing needs can be consistent with showing each of many different individuals the same robust degree of concern. It is therefore worth asking (as I will below) whether members of modern liberal democracies owe one another duties of equal concern that in turn justify health-promoting policies and institutions that tilt in favor of aiding the worst off.

\section{Third Type of Relational Egalitarianism: Social Egalitarianism}

The third kind of relational egalitarianism I want to identify is a brand of what I will call social relationism. This sort of view is found in Elizabeth Anderson's work, in which she argues that distributive justice is not about producing a certain pattern of health or well-being between persons, but rather about fostering mutually respectful interactions between them. According to

\footnotetext{
${ }^{34}$ Nagel, Equality and Partiality, 68.
} 
Anderson, the ideal of equality is best conceived as "a social relationship...[T]wo people [are] equal when each accepts the obligation to justify their actions by principles acceptable to the other, and in which they take mutual consultation, reciprocation, and recognition for granted. ${ }^{, 35}$ In this sort of view, 'equality' once again does not characterize a relationship between two (or more) quantities, nor does it betoken similarity in the degree of other-regarding concern; rather, it suggests a character that the interactions between two (or more) individuals should display. Along these same lines, Samuel Scheffler has also argued that individuals are equal in the morally relevant sense when they can or do interact with one another "as equals," or "on a footing of equality. ${ }^{, 36}$ And as already noted, Hausman and Waldren claim that there are six different objectives that social egalitarians (which Hausman and Waldren call "nonfundamentalist egalitarians") will emphasize as important to a society of equals. For the social egalitarian, distributive inequalities are objectionable when they frustrate the realization of distinct social relational ideals. Hausman and Waldren's six ideals are: procedural fairness, impartiality, everyone's possessing a firm basis for self-respect, the display of equal respect, the cultivation of fraternity, and the prevention of domination. ${ }^{37}$ Thus like the other two kinds of relational egalitarianism I have described, but unlike telic luck egalitarianism, social egalitarianism gives explicit primacy to palpable social evils that connect up in obvious ways to central human interests.

One worry about social egalitarianism is that its driving values and ideals may be too vague to explain what we owe to each other with respect to things like health. For example, Scheffler claims that "human relations must be conducted on the basis of an assumption that

\footnotetext{
${ }^{35}$ Anderson, "What is the Point of Equality?," 313.

${ }^{36}$ Scheffler, "What is Egalitarianism?" 26, 23.

${ }^{37}$ Hausman and Waldren, "Egalitarianism Reconsidered," 578.
} 
everyone's life is equally important." Yet it is not yet clear whether this requires individuals to share a stranger's fate by making sacrifices to help improve his health. Does one owe this to all strangers, or just certain ones? Scheffler leaves such questions unanswered. Further, while it is clearly true that the disabled should be presented with a social world that treats them as equals and that is not hostile to their differences, it may seem in principle possible to eliminate the stigma associated with certain disabilities without requiring expensive, publicly-funded measures to prevent or eliminate those disabilities in the first place. Is a single-minded focus on reducing stigma all that is required by social egalitarianism?

I raise these issues not to dismiss social egalitarianism. It is, after all, hard to deny that justice requires institutional arrangements that treat citizens "as equals" and situate them "on a footing of equality." The same goes for Anderson's claim that justice militates against hierarchy and marginalization. However, these attractive claims do not yet tell us all that what we need to know when we seek to evaluate inequalities in health.

In this section I have described three kinds of relational egalitarianism. Unlike telic luck egalitarianism or prioritarianism, each follows Ross in stressing the moral importance of specific, real-world relationships. Moreover, the first two- equality of treatment and equality of concern - join telic egalitarianism in requiring equality of something: equality of treatment requires "equal social helps and hindrances," whereas equality of concern requires the display of equal degrees of concern for each member of a morally significant group (such as a political community). By contrast, the third form of relational egalitarianism, social egalitarianism, interprets equality not as a relationship between quantities (of benefits) or degrees (of concern), 
but rather as a morally attractive type of relationship, one involving mutually respectful interaction and discourse conducted "on a footing of equality."

\section{Combining the Threads}

As I have indicated, my own view is that the distinct relational egalitarian views are not competitors, and that each describes a plausible plank of distributive justice. Whether and how each bears on the evaluation of health inequalities is a harder question. In this section I want to say a bit more about how the three relational egalitarian views might be brought together to form the core of a pluralistic approach to distributive justice. In section 5 I will attempt to connect the pluralistic approach to the case study provided in this volume by Sarah Horton and Judith C. Baker concerning the oral health of Latino children.

To begin combining the theoretical threads, note that the basis of the equal treatment view, causal relationism, is endorsed by virtually all conceptions of distributive justice, including libertarianism. Causal relationism, again, is the view that the strength of one's moral reason to redress disadvantages depends greatly on one's past causal relation to that disadvantage. And libertarians tend to agree that if one causes harm to another, or if a government policy causes harm to members of society, then redress and restitution are owed. But it is of course true that libertarians will reject the aspect of the equality of treatment view that enjoins the provision of equal helps and hindrances to each member. So where does this demand come from? Pogge is quiet on this, but in my view this demand must also derive from the nature of the cooperative relationships that members of a society stand in with one another. For example, on the assumption that governments legitimately engage in broad macroeconomic management and steering — an assumption shared by Pogge and Nagel—many social laws and policies will 
conspire to yield a hierarchy of jobs and roles. Yet it is implausible to say that the relative size of a given worker's contribution to economic prosperity is proportional to the size of the salary or wage he or she earns. Jobs and roles "at the bottom" have to be taken up by someone, and those of us who do not have to take them are typically relieved that this is so. Each occupant of a useful role therefore accepts a bundle of burdens and benefits that arguably renders each occupant's net social contribution more or less equal. (I put the stress on arguably because I admit that more must be said to defend this conclusion.) If members' net social contributions are indeed roughly equal, then this would support the view that in addition to avoiding and redressing socially caused harm, social policies must further ensure that each member of society receive roughly equal benefits from social cooperation.

Suppose for the sake of argument that Pogge and Nagel can in fact build these additional theses into their equal treatment view. Even so, their view would not require the redress of (to use Pogge's words) "preexisting inequalities in, for example, genetic potentials and liabilities." After all, on Pogge's and Nagel's equal treatment view, if society doesn't cause the health problems, then they “are not society's responsibility and are not to be corrected or compensated at the expense of those favored by these [purely natural] inequalities." ${ }^{38}$ It is at this point that Dworkin's and Miller's relational "equality of concern" view can be brought in to supplement the equal treatment view. For according to Dworkin and Miller, the very forms of social cooperation that Pogge and Nagel can cite to require equality in social "helps and hindrances" can also be cited to defend the requirement that fellow citizens display robust and equal concern for one another. Miller is particularly helpful here, as his view highlights the ways in which actually existing democratic capitalism differs from laissez-faire libertarianism. While many

\footnotetext{
${ }^{38}$ Pogge, "Responsibilities for Poverty-Related Ill Health," 75-6.
} 
self-avowed libertarians have no problem with state-protected private property, national defense, public schools, and public police forces, modern capitalism evidently requires even more in the name of stability and prosperity. Examples here include the central bank's role in setting the key price in the entire economy (the interest rate), a tool that has been used in the United States to deliberately put and keep working people out of work in the name of price stability; the central bank's role as lender of last resort; the state's bestowal of limited liability to corporate entities; and government granted monopolies in the form of patents. After highlighting these and other functions of modern governments, Miller (in effect) argues that a focus on providing equal helps and hindrances is misguided:

Equal concern is the more appropriate standard because it better reflects the moral significance of democratic citizenship. For equal concern, not concern for equal benefit, expresses the proper valuing of the institutional loyalties on which a well-ordered democracy depends. Morally responsible citizens of a just polity want its functioning to depend on willing civic commitments—-for example, a preference for principled persuasion and empathic consideration of others' conflicting interests even when one could be part of a dominant coalition; a willingness to conform to laws with which one disagrees, even if they are somewhat unjust or quite foolish; and, if need be, a willingness to risk one's life for one's country. A proper appreciation of these shared institutional loyalties is displayed in equal concern for one's loyal coparticipants. ${ }^{39}$

I believe the general thought here is that when you continue to cooperate with me even though I help to coerce you through support for laws that you may not fully agree with, I owe you something significant in return (and vice versa). We might say (although Miller does not) that

${ }^{39}$ Miller, “Too Much Inequality,” 298. 
what we give to one another in the course of normal political cooperation is the sort of thing sports commentators refer to as an "intangible": it doesn't necessarily show up in a breakdown of yearly economic statistics, but it deserves special recognition nonetheless. This recognition, Miller suggests, should take the form of special concern for those whose lives one helps to coerce and whose civic cooperation one relies upon.

This account of how a duty of equal concern arises does, I admit, suggest that equality of concern and equality of treatment are competitors. Indeed, Miller explicitly says that equality of concern is a "more appropriate standard" of social justice than is equal benefit. But I do not agree that they are competitors. Consider a more personal analogy. Suppose a parent and his adult child agree to go into business together, splitting profits in half. I assume it is uncontroversial that such an arrangement generates a pro tanto duty on behalf of each to share the profits equally with the other. But the presence of such a duty is perfectly consistent with the presence of distinct duties of parental and filial love and concern. Thus, even if their business contract gives each a pro tanto equal claim on the business's profits, it can still be all-things-considered wrong for (say) the parent to insist on an equal share. If the child is experiencing a financial rough patch while the parent is already financially comfortable, a parental duty of love and concern may well carry the day and count against equal shares. If this is plausible, I think something similar can be said about the political case. That is, the equal treatment view can be correct that roughly equal contributions generate pro tanto claims to roughly equal shares of the social output. And yet the circumstances of social cooperation that Miller highlights can also generate further pro tanto obligations of concern for one's fellow cooperators. Of course, merely drawing attention to this potential blend of pro tanto duties does not yet make it clear what this means in practice. But I 
do think it shows that we needn't view equality of helps-and-hindrances and equality of concern as competitors.

What about the third relational egalitarian view, social egalitarianism? Does that somehow conflict with the other relational views? I noted in section 3 that while social egalitarianism does embody certain important values, these values are highly abstract. This has not prevented some social egalitarians from making bold claims about the view's implications for health justice. For example, Elizabeth Anderson holds that social egalitarianism gives each citizen

a claim to a capability set sufficient to enable them to function as equals in society...Democratically relevant functionings include adequate safety, health and nutrition, education, mobility and communication, the ability to interact with others without stigma, and to participate in the system of cooperation. ${ }^{40}$

But Anderson does not offer a substantive defense of this conclusion, and until she does so it will continue to be reasonable to question her move from the fairly abstract ideal of social equality to the conclusion that citizens have "claims to health." 41

In elaborating his own social egalitarian view, Daniel Hausman says that, "The strongest egalitarian criticisms of domestic inequalities in health rest, I think, on the values of solidarity and reciprocity, which, as I argued above, I take to be themselves [relational] egalitarian values."42 He continues: "To permit some to suffer, to die or to be disabled needlessly is to fail to embrace them as partners in the human enterprise... But the extent to which solidarity is possible

\footnotetext{
${ }^{40}$ Anderson, "Justifying the Capability Approach," 83.

${ }^{41}$ For an in-depth exploration of these and related issues, see Voigt and Wester, "Relational Equality and Health." Regrettably, Voigt and Wester's very nice paper appeared too late for me to engage adequately with it here.

${ }^{42}$ Hausman, "Injustice and Inequality," 40.
} 
across national borders is limited, and this argument has less application to international inequalities. ${ }^{\text {"43 }}$ This view, however, raises the following worry: if the "application" (to use Hausman's term) of solidarity at the domestic level depends upon the contingent fact that the sentiment of solidary just happens to be felt at that level, doesn't the ideal of solidarity lose its normative force? Unless more is said, it is hard to see why failing to feel solidarity across boarders should be thought a permissible failing, whereas failing to feel it within borders is to be viewed as a moral flaw that can be corrected with (or at least counterbalanced by) coercively enforced health-promoting institutions. Unfortunately, Hausman does not say more. But this gap may in fact be an opportunity. For if Hausman embraced something like the argument for equality of concern, he could cite that as the basis of why robust solidarity is owed at the domestic level, but not across borders. This would leave the broad contours of Hausman's view intact, and his view would be defensible for precisely the reason he indicates: participants in a domestic political project are partners in a morally relevant human enterprise, and the nature of their partnership does impose objective moral requirements to display solidarity and reciprocal concern for one another. This, as we have seen, is basically Miller's thesis, and I think this in turn shows how equality of concern and social egalitarianism can be mutually supporting (if not entirely overlapping).

\section{Relational Egalitarianism and Oral Health Disparities}

Sarah Horton and Judith C. Barker's discussion in this volume of oral health in Latino farmworker children in California provides a case study that I believe implicates all three relational egalitarian threads I have highlighted. I want to end with an all-too-brief discussion of

\footnotetext{
${ }^{43}$ Ibid.
} 
how the pluralistic framework I've developed can potentially inform our discussion of whether and how inequalities in oral health raise issues of distributive justice.

As it happens, the first step is the same for both the epidemiologist and the causal relationist, and that is to ask about causes. At first blush, however, it is not clear that oral ill health among the studied population is the result of third-party harm that can directly ground duties of compensation and restitution. At one point in their discussion of causes, Horton and Barker refer to Nancy Krieger's work showing "how the excess risk of hypertension among African Americans is the physical embodiment of myriad social and material factors-including residential and occupational segregation, exposure to toxic substances, interpersonal discrimination..." Here, identifiable and independently unjust social practices contribute to instances of poor health that thereby inherit the unfairness of their causes. But it is not clear that the oral health issues that Horton and Barker focus on are like that. According to Horton and Barker, the proximate causes of oral ill health are the diet and feeding practices of the children's parents. Extensive bottle feeding in early childhood, combined later with sodas, candies and processed foods, do predictably lead to tooth decay. But here the proximate causative agents are the parents who have migrated to California to give themselves and their children a better life and who must permit others to bottle feed their children while breast-feeding mothers are out working in the field. It is hard to treat these causes as morally on a par with the social causes of African American ill health that Krieger outlines.

Proximate causes are, however, just one morally relevant factor. As we have seen, even causal relationists like Pogge and Nagel hold that equal treatment requires a fair distribution of the benefits and burdens of social cooperation, and it would therefore be open to them to argue that oral ill health can be unjust either if its proximate causes are inherently unjust or if it is the 
indirect result of an unjust distribution of economic resources. And it is quite clear that one upstream (though not that far upstream) factor relevant here is the very poor access to pediatric dental care available to the children of migrant farmworkers. Horton and Barker report that California's dental program under Medicaid, Denti-Cal, has such low provider reimbursement rates that "[w]ithin a 50-mile radius of Mendota—a catchment of roughly 800,000—only five dentists accepted children under five insured by Denti-Cal.” And even when children do manage to see a dentist, Denti-Cal's "high standards for proof of service" can mean that (as one dentist put it) "[Y]ou keep sending in your Xrays and get your reimbursements denied, you get frustrated. As a result, there are very few dentists who do pulpotomies on Denti-Cal patients in the area." This encourages under-reimbursed and over-worked Denti-Cal providers to simply extract diseased teeth, rather than restore them. While the argument cannot be fleshed out fully here, one can easily imagine Pogge or Nagel arguing that this arrangement fails to give these families and their children their fair share of social resources. Thus, even if justice does not require a dedicated concern with this population's oral health, it can require a dedicated concern with the fair distribution of background resources, which individuals would then predictably use to promote their own health. This is how an unjust distribution of resources can turn into an unjust cause by the lights of a principle of equal treatment.

A principle of equal concern can take this indictment one step further, by offering to take an active concern in Latino children's oral health itself, and not just in their access to all-purpose resources. ${ }^{44}$ For as Horton and Barker explain, a great many (perhaps the vast majority) of these

\footnotetext{
${ }^{44}$ I assume, along with Ross, that there is always a reason to help those who need help, even in the absence of a special relationship to them. Since I am now trying to explain how the three relational views might work in practice, I'm choosing not to stress the relevance of nonrelational benevolence. But in the end, such benevolence might be among the strongest reasons to help the children at issue. I thank Dan Hausman for pressing me on this point.
} 
children are US citizens. (Although I cannot take up the issue here, it is arguable that those who are not citizens now would be eligible to become citizens under a more just immigration system.) If Miller and Dworkin are correct that responsible citizenship carries with it a claim to the concern of the political community, then the demands of justice might not run out once resources had been distributed as a principle of equal treatment alone would require. Further adjustments may be needed to ensure that proper concern is being showed to those whose needs are especially pressing. Everyone knows that rotting teeth can be physically painful, and as Horton and Barker demonstrate, the lifelong social stigma associated with bad or missing teeth can be piercing and traumatic. So if a principle of equal concern should be combined with a principle equal treatment, that would add further support to policies aimed at redressing the poor health of the worst off - not as a way of evening out the distribution of health-related resources, but rather as the expression of active concern for the well-being of those to whom one is specially politically related and whose needs are especially pressing.

At some point, wanting nicer teeth ceases to be a desire for improved health and becomes a desire merely for improved social status. And it is here where relational egalitarian concerns may appear especially relevant. But just how they are relevant is not immediately unclear, since a main aim of relational egalitarianism is to combat and eliminate unjustified bases of stigma and status differences. Indeed, a good case can be made that the social status conferred by beautiful teeth—as opposed to merely healthy teeth—is unjust and should not be further entrenched by public policy. Consider, for example, a potential letter that Elizabeth Anderson imagines people receiving along with "compensation checks" from the (fictional) State Equality Board:

To the ugly and socially awkward: How sad that you are so repulsive to people around you that no one wants to be your friend or lifetime companion. We won't make it up to 
you by being your friend or your marriage partner - we have our own freedom of association to exercise - but you can console yourself in your miserable loneliness by consuming these material goods that we, the beautiful and charming ones, will provide. And who knows? Maybe you won't be such a loser in love once potential dates see how rich you are.

Anderson herself concludes: "Could a self-respecting citizen fail to be insulted by such messages? How dare the state pass judgment on its citizens' worth as workers and lovers!" ${ }^{45}$ Does this mean, then, that a relational egalitarian cannot justify tax-financed dental care for those whose are stigmatized or ostracized because their teeth aren't straight enough or attractive enough? In later work Anderson concedes that the social roots of stigma can be so difficult to extirpate that tax-financed beautification may well be the only feasible way deliver justice to stigmatized individuals. She now imagines a different, more defensible letter:

Dear Citizen, Your critique of the ways society stigmatizes you and fails to accommodate your differences exposes an injustice in society, which we are working to correct. Unfortunately, we have found that it is difficult to change unjust habits of stigmatization held by the populace against people with your physical appearance. Hence, we are offering you the alternative of plastic surgery, so that you can escape this unjust stigma. ${ }^{46}$ I have no doubt that most social egalitarians would claim that their central concerns can also justify policies aimed at individuals' oral health, not just at their oral beauty. But if healthpromoting policies can already be grounded in the relational planks of equal treatment and equal concern, it may be best to draw most heavily on social egalitarianism when responding to the

${ }^{45}$ Anderson, "What is the Point of Equality?" 305.

${ }^{46}$ Anderson, "Justifying the Capability Approach," 96. 
unjust stigma that attends missing, cracked, or stained teeth. Anderson's discussion shows us how to do this.

\section{Conclusion}

In this essay I have explained the difference between telic egalitarianism (which is at the heart of many luck egalitarian views) and relational egalitarianism, and I have described three different types of relational egalitarianism. In the end, I think that each of the three has an important role to play in our thinking about distributive justice and in our subsequent evaluation of health inequalities. I began my discussion of relational egalitarianism by expressing sympathy with Ross's relational critique of utilitarianism. As is well known, Ross's positive view has been very influential within bioethics, and his is by far the most famous version of moral pluralism. But Ross's view, and many of the discussions of it that exist in the bioethics literature, suggest that there is some single principle of distributive justice, which in turn is just one principle in a fuller moral view. I have argued here that there is in fact more than one principle of distributive justice, and indeed more than one principle of relational egalitarian distributive justice. I hope my discussion helps to clarify the normative and conceptual landscape against which debates about justice and health inequalities should take place.

\section{Bibliography}

Anderson, Elizabeth. "What is the Point of Equality?" Ethics 109 (1999): 287-337.

Anderson, Elizabeth. "Justifying the Capability Approach to Justice." In Measuring Justice: Primary Goods and Capabilities, edited by Harry Brighouse and Ingrid Robeyns, 81-100. Cambridge: Cambridge University Press, 2010.

Crisp, Roger. "Equality, Priority, and Compassion.” Ethics 113 (2003): 745-763.

Dworkin, Ronald. Sovereign Virtue. Cambridge, MA: Harvard University Press, 2002. Dworkin, Ronald. Is Democracy Possible Here? Princeton: Princeton University Press, 2008. 
Hausman, Daniel and Matthew Waldren. "Egalitarianism Reconsidered," Journal of Moral Philosophy 8 (2012): 567-586.

Hausman, Daniel. "Injustice and Inequality in Health and Health Care." In Justice, Luck \& Responsibility in Health Care, edited by Yvonne Denier, Chris Gastmans, and Antoon Vandevelde, 29-42. Dordrecht: Springer Science and Business Media, 2013.

Kelleher, J. Paul. "Capabilities versus Resources," Journal of Moral Philosophy (forthcoming).

Kelleher, J. Paul. "Beneficence, Justice, and Health Care," Kennedy Institute of Ethics Journal 24 (2014): 27-49.

Marmot, Michael. The Status Syndrome: How Social Standing Affects Our Health and Longevity. New York: Henry Holt, 2004.

Miller, Richard W. Globalizing Justice: The Ethics of Poverty and Power. Oxford: Oxford University Press, 2010.

Miller, Richard W. "Too Much Inequality,” Social Philosophy and Policy 19 (2002): 275-313.

Nagel, Thomas. "Equality. In Thomas Nagel, Mortal Questions: 106-127. Cambridge, UK: Cambridge University Press, 1979.

Nagel, Thomas. Equality and Partiality. Oxford: Oxford University Press, 1995.

Nagel, Thomas. "Justice and Nature," Oxford Journal of Legal Studies 17 (1997): 303-321.

Norman, Richard. "Equality, Priority, and Social Justice," Ratio 12 (1999): 178-194.

O’Neill, Martin. "What Should Egalitarians Believe?" Philosophy and Public Affairs 36 (2008): 119-156.

Parfit, Derek. "Equality and Priority," Ratio 10(1997): 202-221.

Pogge, Thomas. "Responsibilities for Poverty-Related Ill Health," Ethics \& International Affairs 16 (2002): 71-81.

Pogge, Thomas. "Relational Conceptions of Justice: Responsibilities for Health Outcomes." In Public Health, Ethics, and Equity, edited by Sudhir Anand, Fabienne Peter, and Amartya Sen, 135-161. Oxford: Oxford University Press, 2006.

Pogge, Thomas. “A Critique of the Capability Approach.” In Measuring Justice: Primary Goods and Capabilities, edited by Harry Brighouse and Ingrid Robeyns, 17-60. Cambridge: Cambridge University Press, 2010.

Ross, W. David. The Right and The Good. Indianapolis: Hackett Publishing, 1930.

Scheffler, Samuel. Boundaries and Allegencies. Oxford: Oxford University Press, 2001.

Scheffler, Samuel. "What is Egalitarianism?" Philosophy \& Public Affairs 31 (2003): 5-39.

Temkin, Larry. "Egalitarianism defended." Ethics 113 (2003): 764-782.

Voigt, Krsitin and and Gry Wester, "Relational Equality and Health," Social Philosophy \& Policy 31(2) (2015): 204-229.

Voigt, Kristin. "Appeals to Personal Responsibility for Health: Reconsidering the Luck Egalitarian Perspective," Cambridge Quarterly of Healthcare Ethics 22 (2013): 146-158. [Erratum: Cambridge Quarterly of Healthcare Ethics 22 (2013): 328-9.] 